\title{
Chilling Requirements to Break Dormancy of Veratrum californicum
}

\author{
Youping Sun and Sarah A. White \\ University, 167 Poole Ag. Center, Clemson, SC 29634 \\ David Mann \\ Infinity Pharmaceuticals, Inc., Cambridge, MA 02139
}

School of Agricultural, Forest, and Environmental Sciences, Clemson

Jeffrey Adelberg ${ }^{1}$

School of Agricultural, Forest, and Environmental Sciences, Clemson University, 275 Poole Ag. Center, Clemson, SC 29634

Additional index words. corn lily, shoot emergence, leaf expansion, photosynthesis

\begin{abstract}
Veratrum californicum, a native of the western United States, has long been used in herbal medicine and now also has potential pharmaceutical uses. As a result of a projected increasing demand for $V$. californicum biomass for pharmaceutical purposes, the development of a chilling protocol for enhanced cultivation efficiency is needed. To study the effects of chilling on the growth of $V$. californicum, field-collected rhizomes with attached bulbs and roots were potted, stored at $10{ }^{\circ} \mathrm{C}$ for 2 weeks, and subsequently chilled at $5^{\circ} \mathrm{C}$ for 30 to 180 days before transfer to a greenhouse or growth room. Twenty plants were transferred to the greenhouse every 30 days to observe growth. Ten plants were harvested at shoot emergence and the remaining 10 when leaves were fully expanded. In addition, 10 plants were transferred from $5{ }^{\circ} \mathrm{C}$ to a growth room every 30 days where net photosynthetic rates were measured. Longer chilling duration correlated with a reduction in days to shoot emergence and leaf expansion. The net photosynthetic rates of $V$. californicum plants chilled for 120,150 , or 180 days were higher than those of plants chilled for only 30, 60, or 90 days. Plants exposed to longer chilling durations were taller and had larger, more numerous leaves. Interestingly, $V$. californicum shoot emergence was also observed in the dark at $5^{\circ} \mathrm{C}$ after the bulbs had been stored for 210 days. Growth of the root systems of plants was also observed during chilling. In conclusion, chilling was necessary at $5{ }^{\circ} \mathrm{C}$ for a minimum of 120 days to force early emergence and vigorous growth of $V$. californicum.
\end{abstract}

Veratrum californicum Durand (corn lily) is an herbaceous perennial monocot native to wet meadows across much of western North America [USDA NRCS (Natural Resources Conservation Service), 2011]. Veratrum californicum has long been used in herbal medicine and now also has potential pharmaceutical applications. In recent years, the $V$. californicum-derived phytochemical cyclopamine and its derivatives have been explored as promising therapeutic agents for the treatment of tumors arising from activation of the Hedgehog signaling pathway (Berman et al., 2002; Chen et al., 2002; James et al., 2004; Taipale and Beachy, 2001; Tremblay et al., 2009). To meet the projected pharmaceutical demand for this alkaloid, a dependable cultivation system will be required. To that end, we are developing cultivation protocols for the greenhouse production of $V$. californicum.

Received for publication 18 July 2012. Accepted for publication 5 Oct. 2012.

We gratefully acknowledge the generous support from Infinity Pharmaceuticals, Inc. that allowed us to conduct the work. We also thank Kenny Krantz for his help in potting, plant care, and data collection.

${ }^{1}$ To whom reprint requests should be addressed; e-mail jadlbrg@clemson.edu.
Extensive field surveys were conducted to select planting stock with high concentrations of cyclopamine and related alkaloids. An ecotype of primary interest was identified in numerous high-elevation bogs and meadows in Utah and Idaho where plants have had the highest yields of alkaloids over several successive years of observation (unpublished data). In these higher (above $2400 \mathrm{~m}$ ) regions with native $V$. californicum populations, bulbs undergo prolonged (seven- to eight-month) periods of winter dormancy under a deep snow pack.

Average daily soil-temperature data collected between 2003 and 2010 at three depths $(5,20$, and $51 \mathrm{~cm})$ from several independent USDA weather station locations in Utah proximal to natural $V$. californicum populations of interest show that soil temperatures typically drop below $10{ }^{\circ} \mathrm{C}$ by 1 Oct. and do not return above $10{ }^{\circ} \mathrm{C}$ until after 1 May. Field observations report a rapid burst of vegetative growth after the recession of the snow line. Taylor (1956) reported that a period of exposure to cold temperatures is necessary to permit successful vegetative growth of $V$. californicum and that this prolonged exposure to cold is essential for successful cultivation. Dormancy is defined as a lack of growth because specific conditions have not been met (e.g., a period of low temperature). We anticipate that a successful production protocol for $V$. californicum collected from natural populations in temperate regions, sites above $2400 \mathrm{~m}$ in elevation, will include defined chilling treatments.

In this study we report the influence of varied periods of chilling on shoot emergence and growth using mature, field-collected $V$. californicum plants. Our goal was to force $V$. californicum to emerge before a hypothetical natural period of snow cover as a means of shortening the production cycle. Thus, we determined the minimum length of cold treatment required to break dormancy and whether shortened dormancy affected shoot emergence and vigor. Growth of the shoot systems was also observed in both greenhouse and artificially illuminated growth rooms.

\section{Materials and Methods}

Chilling. A few hundred plants of Veratrum californicum, rhizomes with attached bulbs and roots, were selected for uniformly large size from a wild population of thousands dug in a meadow $\approx 1000 \mathrm{~m}^{2}$ (mechanically harvested for the purpose of pharmacological research) in Boulger Canyon, UT (lat. 39 $36^{\prime} \mathrm{N}$, long. $111^{\circ} 13^{\prime} \mathrm{W}$, elevation $2671 \mathrm{~m}$ ). This site was chosen because the planting stock from which the plants were collected had high concentrations of cyclopamine and related alkaloids (unpublished data). The next day, 14 Sept. 2010, plants were shipped overnight to Clemson, SC, and on arrival, the rhizomes, each with one bulb, were sorted into two size groups based on bulb circumference [12.2 \pm $1.0 \mathrm{~cm}$ (mean $\pm \mathrm{SD})$ and $10.2 \pm 1.4 \mathrm{~cm}$ for large and small bulb sizes, respectively] and potted into 7.6-L (large) or 3.8-L (small) plastic containers filled with Fafard 3B mix [45\% Canadian sphagnum peatmoss, $25 \%$ processed pine bark, $15 \%$ perlite, $15 \%$ vermiculite, starter nutrients (40 to $230 \mathrm{mg} \cdot \mathrm{L}^{-1}$ nitrogen; 5 to $30 \mathrm{mg} \cdot \mathrm{L}^{-1}$ phosphorus; 40 to $200 \mathrm{mg} \cdot \mathrm{L}^{-1}$ potassium, calcium, and sulfur; 25 to $80 \mathrm{mg} \cdot \mathrm{L}^{-1}$ magnesium), wetting agent, dolomitic limestone; Conrad Fafard, Inc., Anderson, SC]. Each plant was drenched with 330 ppm Subdue ${ }^{\circledR}[25.1 \%$ Metalaxyl: $N$ (2, 6-dimethylphenyl)- $N$-(methoxyacetyl) alanine methyl ester, $74.9 \%$ inert ingredients; Syngenta Crop Protection, Inc., Greensboro, $\mathrm{NC}]$ to prevent root rot.

Veratrum californicum plants were first stored in the dark at $10{ }^{\circ} \mathrm{C}$ and $70 \%$ relative humidity for 2 weeks (pretreatment) and then chilling treatments were initiated at $5{ }^{\circ} \mathrm{C}$ and $65 \%$ relative humidity for $30,60,90,120,150$, and $180 \mathrm{~d}$ in a controlled environment room (Model\# 120-208; Climate Technologies, Inc., Laytonsville, MD) in the Clemson University Biosystems Research Complex. Bulbs and rhizomes not included in these experiments were handled in the same manner as experimental units and were retained under experimental conditions for $220 \mathrm{~d}$. All bulbs and rhizomes were watered at 2-week intervals and substrate volumetric water content was maintained above $44.2 \% \pm 5.8 \%$ as measured 
using Decagon 10-HS soil moisture sensors (Decagon Devices, Inc., Pullman, WA).

Greenhouse and growth room forcing. Nineteen plants from each bulb size treatment were removed from the cold environment room on a monthly basis. Four plants were destructively harvested for analysis (harvest described subsequently), 10 plants transferred into a greenhouse, and five plants transferred into a growth room. Both the greenhouse and growth room are located in the Clemson University Biosystems Research Complex.

Plants transferred to the greenhouse environment were fertigated with $100 \mathrm{mg} \cdot \mathrm{L}^{-1}$ nitrogen CalMag special fertilizer $(15 \mathrm{~N}-$ 2.2P-12.5K; Scotts Peters Excel, Marysville, $\mathrm{OH})$. Substrate volumetric water content was measured by using Decagon10-HS soil moisture sensors and maintained at or above $48.5 \% \pm 4.9 \%$. An ECD DataWorker (ECD, Inc., Milwaukie, OR) recorded canopy air temperature on an hourly basis. Ambient air temperatures in the greenhouse were 20.2/ $17.0 \pm 6.5 / 5.2{ }^{\circ} \mathrm{C}$ day/night during the experimental period. Light intensity at the canopy level was monitored hourly with LI-190 Quantum sensors (LI-COR ${ }^{\circledR}$ Biosciences, Lincoln, NE) and a LI-1400 data logger (LI-COR ${ }^{\circledR}$ Biosciences). The average daily light integral over the experiment period was $\approx 23.3 \mathrm{~mol} \cdot \mathrm{m}^{-2} \cdot \mathrm{d}^{-1}$.

Plants in the growth room $(3 \mathrm{~m} \times 3 \mathrm{~m})$ were fertigated with $100 \mathrm{mg} \cdot \mathrm{L}^{-1}$ nitrogen CalMag special fertilizer every other day, and substrate volumetric water content was maintained above $41.2 \% \pm 5.3 \%$. Ambient air temperature in the growth room was $23.1 \pm$ $0.7^{\circ} \mathrm{C}$ during the light and dark period. Light, during a 12-h photoperiod, was provided with 1000-W metal halide lamps (Agrosun Gold; Hydrofarm, Inc., Medley, FL), which were placed $1.5 \mathrm{~m}$ above the bench. Light intensity at the plant canopy surface was $16.0 \pm 0.6$ $\mathrm{mol} \cdot \mathrm{m}^{-2} \cdot \mathrm{d}^{-1}$. Relative humidity in the growth room was maintained at $43.1 \% \pm 8.2 \%$ by using an Argus humidity controller (Argus Control Systems Ltd., British Columbia, Canada).

Data collection. Times to shoot emergence $(\approx 2$ to $5 \mathrm{~cm}$ long bud emergence from bulb) and leaf expansion (a minimum of three fully expanded leaves) were recorded for plants in both bulb size treatments in the growth room (shoot emergence $n=5$; leaf expansion $\mathrm{n}=5$ ) and greenhouse (shoot emergence $n=10$; leaf expansion $n=5$ ). The time to shoot emergence and leaf expansion began (Day 0) when plants were moved from the chiller (i.e., the end of treatment) into their growth environment. In the greenhouse, five $V$. californicum plants from each bulb size treatment were harvested at shoot emergence and at leaf expansion. At harvest, the number of newly developed roots was counted. Plant parameters measured once plants reached maturity, defined as the end of leaf expansion, included plant height $(\mathrm{cm})$ from the bulb basal plate to the top of the stalk, the number of leaves per plant, and length and width $(\mathrm{cm})$ of five leaves counted upward from the second most mature leaf at the base of the stalk. At the end of the experiment (24 May), dead plants were counted.

Photosynthetic light response curves were recorded for all plants surviving after $40 \mathrm{~d}$ in the growth room by using a CIRAS-2 portable photosynthesis system with an integrated Chlorophyll Fluorescence Module (CFM) unit (PP Systems International, Inc., Amesbury, MA) mounted with an automatic universal PLC6 broad leaf cuvette. All plants were well watered before measurements. The third, fourth, or fifth fully expanded leaf, counting from the top of the plant downward, was chosen for the measurements. Two of the three leaves per plant were recorded. The number of plants measured per chilling period for which photosynthetic light response curves were recorded include one, five, nine, 10 , nine, and eight from $30,60,90,120,150$, and $180 \mathrm{~d}$ of chilling, respectively. The $\mathrm{CO}_{2}$ concentration within the leaf chamber was maintained at $375 \mu \mathrm{mol} \cdot \mathrm{mol}^{-1}$, whereas the photosynthetic light response curve was measured. Constant temperature $\left(25^{\circ} \mathrm{C}\right)$ and relative humidity $(75 \%)$ were maintained within the leaf cuvette during each measurement Before each response curve was measured, the leaf clamped inside the leaf cuvette was exposed to a dark adaptation period of $30 \mathrm{~min}$. Light intensities were gradually increased from 0 to $2000 \mu \mathrm{mol} \cdot \mathrm{m}^{-2} \cdot \mathrm{s}^{-1}$ at $200 \mu \mathrm{mol} \cdot \mathrm{m}^{-2} \cdot \mathrm{s}^{-1}$ light intervals. The minimum holding time between each step was $45 \mathrm{~s}$.

Statistical analysis. Plants were assigned to treatments in a completely randomized design. Data were analyzed with JMP Version 9.0 (Statistical Analysis System, Cary, NC). Main effects and interactions among chilling duration, bulb size, and/or location/stage were analyzed using a three-way analysis of variance. Each plant was considered as an experimental unit. Linear and quadratic trend analyses were also conducted.

\section{Results and Discussion}

Shoot emergence, leaf expansion, and root regeneration. Chilling duration significantly affected shoot emergence and leaf expansion $(P<0.0001)$ irrespective of bulb size or growing condition (growth room or greenhouse). As the duration of chilling increased, the time required for shoot emergence (Fig. 1A) and leaf expansion (Fig. 1B) decreased. Langens-Gerrits et al. (2003) also observed that shoot emergence from dormant bulblets of Lilium speciosum 'Rubrum No. 10 ' occurred more quickly with greater uniformity after a longer chilling ( 6 weeks vs. 4 weeks) duration at $5{ }^{\circ} \mathrm{C}$. Before $120 \mathrm{~d}$ of chilling, it took shoots and leaves a prolonged time to emerge and expand (Figs. 1A-B). These data suggest that longer (greater than $120 \mathrm{~d}$ ) chilling periods may not significantly affect days to shoot emergence and leaf expansion. However, the quality of plant growth (visual observations) continued to improve with longer chilling periods. None of the plants in our study flowered. Flowering in $V$. californicum
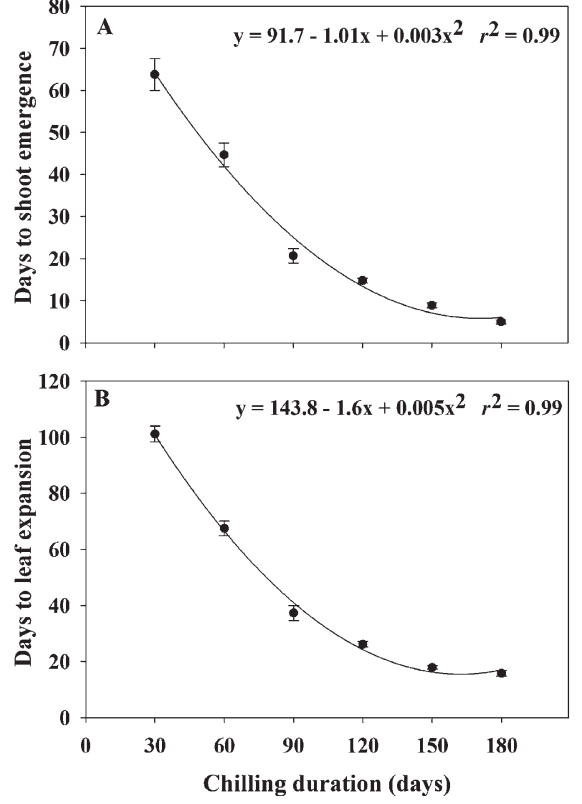

Fig. 1. Effect of chilling duration at $5{ }^{\circ} \mathrm{C}$ on Veratrum californicum shoot emergence (A) and leaf expansion $(\mathbf{B})$. Vertical bars represent the SEM observed for shoot emergence $(\mathrm{n}=30)$ and leaf expansion $(\mathrm{n}=20)$. Data were pooled by bulb size and growing condition because no significant differences were noted.

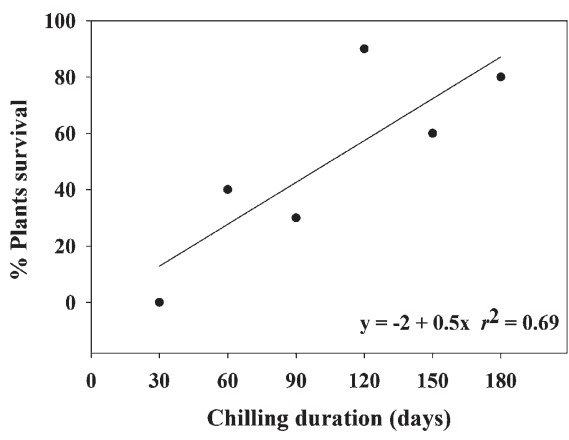

Fig. 2. The effect of chilling duration at $5{ }^{\circ} \mathrm{C}$ on percent survival of Veratrum californicum plants grown in a temperature-controlled growth room $(\mathrm{n}=10$, per chilling treatment duration).

is sporadic (Taylor, 1956), and the potential to flower may be predetermined during the preceding season of growth.

New roots began to form during the first 30 - $\mathrm{d}$ chilling treatment, and root formation continued over the entire range ( 30 to $180 \mathrm{~d}$ ) of chilling treatments. New primary roots formed on $10.3 \%$ (19 of 184) of bulb plates; there was an average of four roots per bulb, which averaged $5 \mathrm{~cm}$ in length. New secondary roots also emerged from the old roots on $88.6 \%$ of bulbs (163 of 184). Chilling duration significantly affected the number of new secondary roots per bulb $(P=0.002)$ with more secondary roots forming on large-sized bulbs $(P=0.0002)$. Additional roots formed after the chilled bulbs were moved into the greenhouse environment $(P<0.0002)$. 
Pak et al. (1995) previously reported that water uptake was facilitated by root growth during chilling and that this was necessary for shoot emergence in onions.

Plant performance in the growth room. Fifty percent of the $V$. californicum plants transferred into the growth room died before the conclusion of the experiment. Among the dead plants, only three plants had a few new secondary roots when examined (data not shown); thus, the lack of root development or loss or new roots may have contributed to the observed high mortality rate. Longer durations
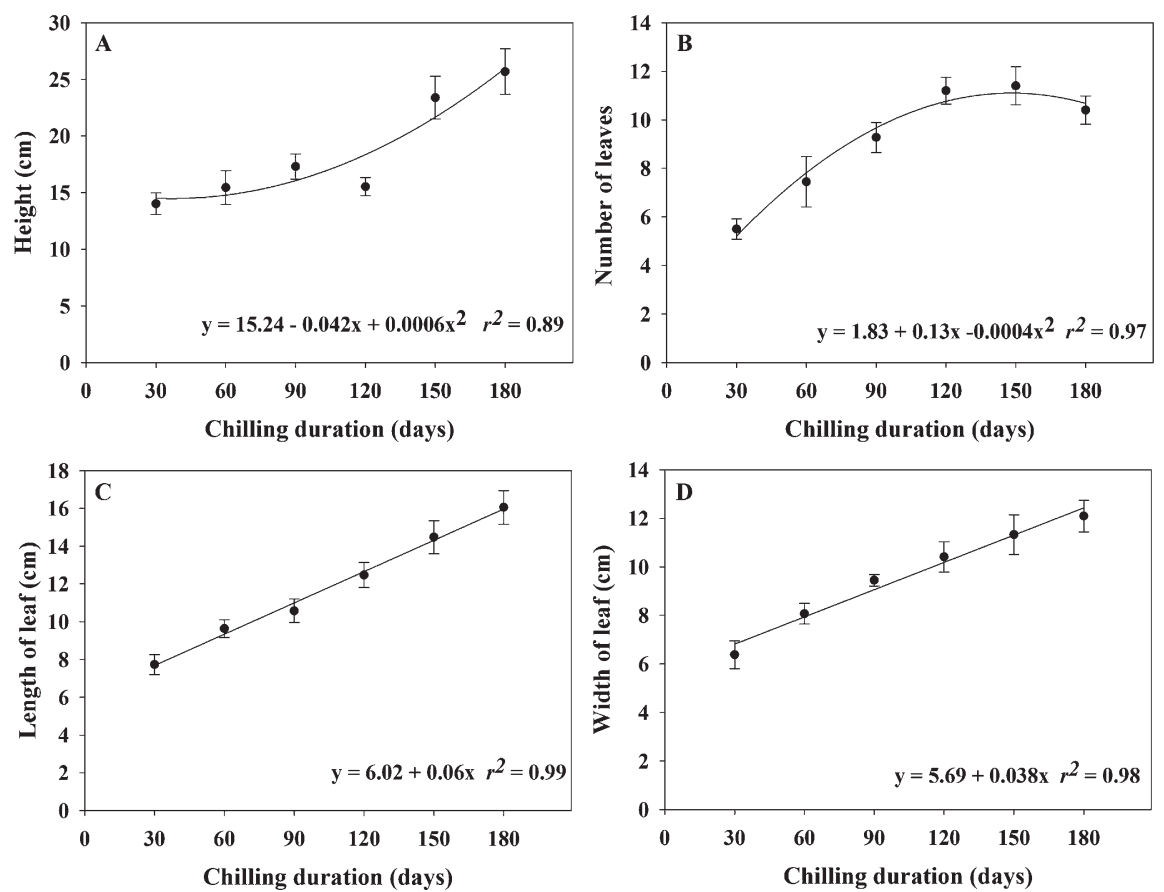

Fig. 3. Chilling duration at $5{ }^{\circ} \mathrm{C}$ influenced Veratrum californicum height (A), number of leaves $(\mathbf{B})$, length (C), and width (D) of leaves after $40 \mathrm{~d}$ of subsequent growth in a temperature-controlled growth room at $23{ }^{\circ} \mathrm{C}$. Vertical bars represent the SEM response of $n=8$ plants for the 30 and $60 \mathrm{~d}$ chilling treatments and $\mathrm{n}=10$ plants for the $90,120,150$, and $180 \mathrm{~d}$ chilling treatments.

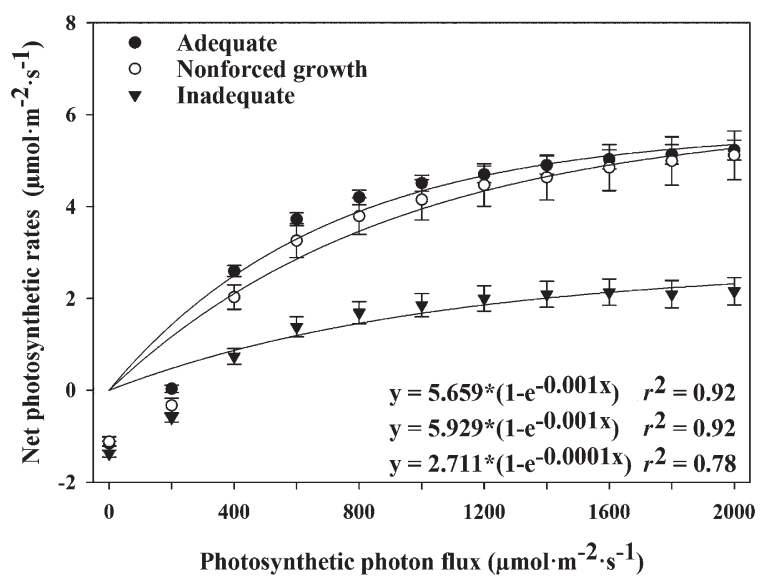

Fig. 4. The influence of chilling duration at $5{ }^{\circ} \mathrm{C}$ on the net photosynthetic rate of Veratrum californicum plants after $40 \mathrm{~d}$ of subsequent growth in a temperature-controlled growth room at $23^{\circ} \mathrm{C}$. Data for plants chilled for 30,60, and $90 \mathrm{~d}$ were pooled (inadequate), and data for plants chilled for 120, 150, and $180 \mathrm{~d}$ were also pooled (adequate). Non-forced plants emerged in the dark after greater than seven months of chilling. Vertical bars represent the SE of the average net photosynthetic rate of inadequate $(n=15)$, adequate $(n=27)$, and non-forced $(n=4)$ plants.
$(P<0.0001$; Fig. 3). Although leaf size (length and width) increased with chilling durations of greater than $120 \mathrm{~d}$, the number of leaves did not increase significantly. The maximum effect of chilling on plant height was observed in durations of greater than $150 \mathrm{~d}$. These results indicate that shoot buds are prepared not only for emergence, but also for subsequent plant growth (leaf expansion) during the chilling period. Langens-Gerrits et al. (2003) reported that $5{ }^{\circ} \mathrm{C}$ cold treatment enhanced size and mass of non-dormant $\mathrm{Lil}$ ium speciosum Thunberg. 'Rubrum No. 10' bulblets compared with non-treated plants. Shin et al. (2002) reported that the physiological dormancy of Lilium 'Casablanca' and Lilium 'Mona' bulblets was released more rapidly with greater shoot production after a 9-week cold treatment at $4{ }^{\circ} \mathrm{C}$ as compared with 9 weeks at either 10 or $25^{\circ} \mathrm{C}$. Although our results indicate that the chilling period influenced the number of leaves, it is possible that the inadequate root mass of plants in chilling treatments of less than $120 \mathrm{~d}$ also may have decreased the potential number of leaves ultimately expanded from the bulb. Veratrum californicum is a facultative wetland plant species and the root system was impacted when lifting plants from the field for our study. Thus, it is possible that inadequate root formation limited water uptake and bulb growth during shorter chilling durations.

The potential net photosynthetic rates of $V$. californicum plants increased during the first $120 \mathrm{~d}$ of chilling. The net photosynthetic rates of leaves emerging from $V$. californicum plants chilled for 30,60 , and $90 \mathrm{~d}(P=$ 0.2 ) did not differ significantly from each other. Nor were there differences in the net photosynthetic rates of plants chilled for 120 , 150 , and $180 \mathrm{~d}(P=0.99)$. Thus, the data were pooled into two groups. One group (inadequate chilling) included the net photosynthetic rates of plants chilled for 30 to $90 \mathrm{~d}$. The other group (adequate chilling) included plants grown from bulbs chilled for 120 to 180 d. Plants chilled adequately had significantly higher net photosynthetic rates than did those with inadequate chilling $(P<$ 0.0001 ). The adequately chilled plants had greater root mass and higher net photosynthetic rates; these attributes may be the result of more massive sink. Sink strength is considered a product of sink size and sink activity (Ho, 1988).

The maximum net photosynthetic rate of plants with adequate chilling was twice that of plants with inadequate chilling (Fig. 4). Plants chilled for more than $210 \mathrm{~d}$ emerged in the cold storage room in the dark (non-forced growth) and had similar photosynthetic rates to plants with adequate chilling periods once shoots were established. These data are consistent with field observations of the Boulger Canyon $V$. californicum ecotype, which can sprout beneath the snow pack under similar environmental conditions $\left(0\right.$ to $\left.5{ }^{\circ} \mathrm{C}\right)$ as those maintained in the growth chamber (observations in Mammoth-Cottonwood, UT, near Boulger Canyon). 
In conclusion, adequate chilling plays a critical role in $V$. californicum growth. A greenhouse production protocol for $V$. californicum will likely need to incorporate a minimum of $120 \mathrm{~d}$ of chilling at $5^{\circ} \mathrm{C}$ as part of the growth cycle. Roots grow during chilling and greater root mass influences subsequent shoot performance. Although our data indicate that maximal photosynthetic rates of plants grown from bulbs chilled for 120, 150, or $180 \mathrm{~d}$ were similar, plant quality parameters differed, and plants with longer chilling durations appeared to be larger and of higher quality as observed by overall appearance. The influence of chilling duration on plant mass and alkaloid production should be examined, because the ultimate purpose of developing a production protocol for $V$. californicum is to develop an alkaloid production system to support pharmaceutical use.

\section{Literature Cited}

Berman, D.M., S.S. Karhadkar, A.R. Hallahan, J.I. Pritchard, C.G. Eberhart, D.N. Watkins, J.K
Chen, M.K. Cooper, J. Taipale, J.M. Olson, and P.A. Beachy. 2002. Medulloblastoma growth inhibition by hedgehog pathway blockade. Science 297:1559-1561.

Chen, J., J. Taipale, and M. Cooper. 2002. Inhibition of hedgehog signaling by direct binding of cyclopamine to smoothened. Genes Dev. 16 : 2743-2748.

Ho, L.C. 1988. Metabolism and compartmentation of imported sugars in sink organs in relations to sink strength. Annual Review of Plant Physiology and Plant Molecular Biology 39:355378.

James, L.F., K.E. Panter, W. Gaffield, and R.J. Molyn. 2004. Biomedical applications of poisonous plant research. J. Agr. Food Chem. 52:3211-3230.

Langens-Gerrits, M.M., W.B.M. Miller, A.F. Croes, and G.J. de Klerk. 2003. Effect of low temperature on dormancy breaking and growth after planting in lily bulblets regenerated in vitro. Plant Growth Regulat. 40:267-275.

Pak, C., L.H.W. van der Plas, and A.D. de Boer. 1995. Importance of dormancy and sink strength in sprouting of onions (Allium cepa) during storage. Physiol. Plant. 94:277-283.
Shin, K.S., D. Chakrabarty, and K.Y. Paek. 2002. Sprouting rate, change of carbohydrate contents and related enzymes during cold treatment of lily bulblets regenerated in vitro. Sci. Hort. 96:195-204.

Taipale, J. and P.A. Beachy. 2001. The hedgehog and wnt signaling pathways in cancer. Nature 411:349-354.

Taylor, C.A. 1956. The culture of false hellebore. Econ. Bot. 10:155-165.

Tremblay, M.R., A. Lescarbeau, M.J. Grogan, E. Tan, G. Lin, B.C. Austad, L.C. Yu, M.L. Behnke, S.J. Nair, M. Hagel, K. White, J. Conley, J.D. Manna, T.M. Alvarez-Diez, J. Hoyt, C.N. Woodward, J.R. Sydor, M. Pink, J. MacDougall, M.J. Campbell, J. Cushing, J. Ferguson, M.S. Curtis, K. McGovern, M.A. Read, V.J. Palombella, J. Adams, and A.C. Castro. 2009. Discovery of a poten and orally active hedgehog pathway antagonist (IPI-926). J. Med. Chem. 52:44004418.

USDA, NRCS (Natural Resources Conservation Service). 2011. PLANTS profile: Veratrum californicum Durand. 5 July 2011. <http://plants. usda.gov/java/profile?symbol=VECA2 $>$. 